Revista Iberoamericana, Vol. LXXIII, Núm. 220, Julio-Septiembre 2007, 665-686

\title{
ALIANZAS Y OPOSICIONES ENTRE INDIOS Y MILITARES DURANTE EL SIGLO XX. UN MODELO SOCIAL ECUATORIANO
}

POR

\author{
SALOMÓN Cuesta Z. \\ FIAAM
}

\author{
Cecilia Ortiz B. \\ FLACSO
}

\begin{abstract}
No es que la gente golpee las puertas de los cuarteles, da verdaderos garrotazos para exigir las intervenciones militares. Las fuerzas armadas han debido actuar en momentos cruciales para los intereses de la Patria, incluso, ante la falta de decisión de las autoridades de turno (Gral. J. Gallardo, entrevista del 24-11-03)
\end{abstract}

Al INICIO fUe LA PALABRA

Las funciones de las fuerzas armadas a favor de la defensa nacional les otorgan un rol político reconocido ampliamente por las leyes y legitimado por el resto de la sociedad; no obstante, los militares son parte de una institución corporativa con intereses particulares que no necesariamente se orienta en bien de la nación que defiende y que es parte, y receptáculo, de los conflictos, crisis de hegemonía y asimetrías presentes en el ámbito civil.

El Estado y los militares buscan perfeccionar y expandir el ámbito de la civilización hasta cubrir todos los espacios de la ciudadanía y los ciudadanos; pretenden construir el continente y contenido de la nación. Esta noción de perfección induce a la participación de los militares en ámbitos que superan sus obligaciones específicas -defensa del frente externo y control del orden interno-, y a que se arroguen para sí el papel tutelar de la democracia y la constitución para preservar en el tiempo y el espacio la nación y el Estado.

Este papel tutelar de la democracia y la Constitución implica, en momentos determinados, ir en contra de esas instituciones, si la soberanía y la seguridad de la nación (la patria) están amenazadas. Esta situación se ha reiterado en numerosas ocasiones en

\footnotetext{
${ }^{1}$ El general Gallardo llegó a ocupar los cargos de comandante general del ejército y ministro de Defensa (1992). En el período desarrollista participó directamente de la organización de cooperativas de la población rural, ocupó la dirección del Banco de Fomento (1989) y terció en una elección presidencial (1996). Fue presidente del Banco del Estado (1997). Volvió al Ministerio de Defensa, cargo que ocupaba en la coyuntura de enero de 2000. Actualmente lidera la campaña presidencial de uno de los candidatos para las próximas elecciones (2006).
} 
Ecuador y forma parte de su cultura política. Las elites civiles, primeras en demandar el cumplimiento del rol no deliberante de las fuerzas armadas, lo han estimulado, al solicitar la intervención militar en situaciones de crisis económicas y/o políticas.

El proyecto civilizatorio liderado por los militares (directa e indirectamente) se articula a tres líneas de construcción: 1) la ideologización de la historia y "militarización de los mitos” (Ginzburg 186), sobre los que descansan los hitos históricos que sustentan la identidad (nacionalidad) ecuatoriana (Ortiz); 2) la visión del Estado moderno, como una actividad basada en consideraciones laicas y no limitadas por concepciones prerracionales (Kaldor) y 3) la concepción del Estado como primordial, necesario y demandante de obediencia absoluta [Estado Máximo] (Buzan).

En este contexto los militares se convierten en adalides de la nación y portaestandartes de la nacionalidad, pues a partir de ellos se interpreta la historia e identidad con base en la utilización del texto vivo que se encuentra en la memoria colectiva y cultura material de la nación. Umberto Eco (17-8), al referirse a la “utilización” del texto, apunta que éste puede ser utilizado para "soñar despierto" y este ejercicio personal induce al autor a moverse en un "bosque narrativo como si fuera [su] jardín privado". Los militares, en este sentido, se convierten en creadores de realidades al construir instituciones que generan sentidos internos (identidades nacionales) y sentidos externos (lealtades y percepciones de pertenencia positiva al Estado) que se convierten en instituciones domeñadas en la forma y en el fondo por la figura estatal.

El presente artículo busca identificar la influencia que ha tenido el proyecto de nación de las fuerzas armadas en la inserción de los indios en la escena pública/política ecuatoriana a inicios del siglo XXI (Ortiz). Los militares han construido un proyecto propio de nación, que implica alianzas situacionales con las elites civiles y se proyectan como el elemento catalizador de la unidad nacional en un país donde la identidad se ha construido sobre la ausencia de una narración aglutinante que convoque en un solo proyecto político a los distintos segmentos étnicos, regionales, políticos e ideológicos del Ecuador.

El planteamiento central de este artículo es que el 21 de enero de 2000 en Ecuador los coroneles que promovieron el golpe de Estado contra el presidente constitucional Jamil Mahuad (1998-2000) usaron a los indígenas organizados como instrumento para llegar al poder en defensa de sus intereses corporativos. Este hecho evidenció que la unidad del movimiento indígena estaba dada por las coyunturas de la política ecuatoriana y los intereses de los individuos y, por otro lado, reveló la crisis institucional de los militares ecuatorianos producida a partir de la firma de la paz con el Perú (agosto de 1998), que modifica la noción del enemigo externo del Ecuador focalizada en la inminencia de un enfrentamiento armado entre los dos países por la frontera no delimitada en la región amazónica.

LA AMBIGUA PERCEPCIÓN DE LO MILITAR EN ECUADOR

Desde la perspectiva académica, el tratamiento del tema militar mantiene distintos matices para el caso ecuatoriano. Por un lado, se concibe que los miembros de la institución son incapaces de actuar en política por su propia iniciativa, sino que lo hacen como resultado del desplazamiento del conflicto político civil al interior de los cuarteles. 
Desde esta visión, su carencia de decisión propia convierte a los militares en instrumentos de las elites civiles (Varas y Bustamante). Desde otro ángulo de interpretación, la participación de las fuerzas armadas en política y ámbitos de acción que en teoría serían de exclusiva incumbencia de la sociedad civil se ve como la figura que adopta periódicamente el poder político en Ecuador. Así se destaca la capacidad decisoria que han tenido los militares en la construcción de la nación y su influencia en la configuración y consolidación del Estado ecuatoriano (Hurtado 177). Otra línea de entendimiento de las relaciones cívico-militares indaga sobre las interconexiones entre los militares y los distintos actores sociales y políticos, y construye un aparato teórico específico, que configura a las fuerzas armadas como actor social y político imbuido en actividades castrenses (Fitch, "Warriors..." 2).

Sin embargo, la interpretación de las fuerzas armadas sufre una crisis en torno al papel que deberían asumir los militares en el contexto de paz con el Perú y frente a las nuevas amenazas a la seguridad del Estado: el narcotráfico y el terrorismo, principalmente, en un contexto donde los procesos de ciudadanización y cambios de la concepción del Estado dirigidos a defender las fronteras nacionales de las agresiones peruanas se ha modificado sustancialmente después de la paz alcanzada en 1998 (García “El 20 de abril”). Crisis de interpretación que no excluye a los militares, quienes no logran superar su propia crisis institucional al perder el papel tradicional de defensa otorgado desde la sociedad civil y desde las funciones políticas asumidas por ellos.

Para fines de este trabajo se plantea que a pesar de la actual crisis institucional, los militares son un actor político con capacidad de ejercer presión a partir de su posición privilegiada dentro del aparato del Estado. Por su condición de defensores de la patria, cuentan con ventajas comparativas que les otorgan capacidades para la intervención directa en el manejo político, ideológico y socioeconómico del país (Rouquié, El Estado 157).

\section{LA UBICUIDAD DE LOS MILITARES EN LA POLÍTICA}

Las fuerzas armadas del Ecuador tienen un amplio margen de decisión que vuelve difuso su accionar. La Constitución respalda expresamente su intervención en asuntos que no son estrictamente militares. El carácter obediente y no deliberante de las fuerzas armadas consta en las diecisiete constituciones republicanas; no obstante, sus funciones son ambiguas, pues transitan entre el desarrollo y la seguridad.

A partir de 1967, el ámbito de acción militar se ensancha en la Constitución al complementarse el texto inicial: "la defensa de la nación frente a los enemigos externos y la conservación del orden interno, garantizando el orden constitucional”, con el inciso: "la colaboración, que sin menoscabo de su misión fundamental [la defensa], presten al desarrollo económico y social del país” (Molina 47 y ss.). En el artículo 183 de la Constitución vigente (1998) consta: “La Ley determinará la colaboración que la fuerza pública, sin menoscabo del ejercicio de sus funciones específicas, prestará para el desarrollo social y económico del país” (Asamblea Nacional Constituyente 78).

Con la revolución liberal (1895), Ecuador inicia el siglo xx en un contexto de jefatura militar. Hasta enero de 2000, se registran más de diez revueltas militares. Durante todo este 
siglo, y tras golpes de Estado apoyados por distintas fuerzas sociales, las fuerzas armadas presiden el ejecutivo o facilitan su ocupación por parte de políticos civiles que cuentan con su anuencia. El 21 de enero de 2000 protagonizan un nuevo golpe de Estado, con la participación de segmentos de las elites indígenas aglutinados en torno a la Confederaciones de Nacionalidades Indígenas del Ecuador (CONAIE). Este evento, ¿ fue el resultado de una alianza coyuntural entre indios y militares o involucró una relación política que iba más allá de los hechos que la rodearon de forma inmediata?

LA OTRA CARA DE LA CIVILIZACIÓN

Una condición para la defensa es la unidad nacional: una nación fragmentada y desigual mal puede defenderse (Paz 27). Ello implica "incorporar al indio y al montubio a la vida civilizada mediante la educación, la elevación económica, la forjadura espiritual la protección de las leyes” (142).

El "soldado de la patria” mantiene una función social y política (Guerrero 33), ${ }^{2}$ un contacto afectivo con la patria. Propicia el progreso y desarrollo -paradigmas de la modernidad- y consigue avances tecnológicos, técnicos, vías de comunicación que acrecienten la capacidad unificadora de la nación para "facilitar el intercambio interno y externo” y la integración de quienes habitan en las tierras más distantes. Todo ello amerita un Estado fuerte, la dirección técnico-económica para el fomento de la agricultura, las industrias y el comercio, y reformas legales pensadas en toda la sociedad (Paz 155). Debe aplicarse una reforma agraria como fórmula para la distribución coherente de la tierra.

Los militares en 1925 (a partir de un golpe de Estado) propician la modernización estatal y económica e implementan leyes para “dignificar la raza indígena” (Velasco 29). El general Enríquez Gallo (presidente de facto 1937-1938), emite la ley de Organización y Régimen de las Comunidades Indígenas ${ }^{3}$ y el Código del Trabajo, que fija el jornal que debe recibir al huasipunguero, ${ }^{4}$ la jornada laboral en el campo, los descansos y el acceso a ciertos recursos de la hacienda.

Lo dicho anteriormente resume la filosofía del militar moderno frente a la temática indígena durante la primera mitad del siglo xx, que proyecta una autopercepción mesiánica y paternalista que se expresa en discursos redentores que hablan de la necesidad del paso a la modernización de las instituciones políticas, económicas y culturales, es decir, el ethos militar como guía de acción y de intención política para incidir en el desarrollo y el progreso de la patria.

La visión mesiánica y paternalista del militar identifica el pathos del progreso en la presencia de un segmento poblacional, que por sus diferencias raciales y sicológicas no está integrado al conjunto de la nación. La identificación de los indígenas como el pathos

\footnotetext{
${ }^{2}$ Hacia el año 1928 el general del ejército Guerrero preside la cartera de Defensa Nacional.

${ }^{3}$ Que reconoce los derechos de la vida cívica y administrativa de caseríos, barrios, comunidades y parcialidades indígenas, sin reconocimiento jurídico hasta aquella fecha.

${ }^{4}$ Este sistema consistía en la asignación al interior de sus predios, por parte del hacendado a los trabajadores, de un pedazo de tierra o huasipungo en el que podían vivir los trabajadores (huasipungueros) con sus familias en una relación de sujeción frente a la hacienda.
} 
del progreso, inferioriza al indígena y condiciona su integración a un proceso de desindianización del que se siente responsable y con el encargo de conseguirlo, ante la necesidad de integración y unidad, por una inminente necesidad defensiva.

En Ecuador, los indios han sido funcionales a los proyectos políticos y económicos de las elites en el poder como fuerza de trabajo: en las obras públicas, en las labores de la hacienda serrana, en las plantaciones de la costa, en los procesos de urbanización e industrialización o como agentes de la modernización del agro. Ello, en un contexto en el que los militares han jugado el papel de promotores de la modernización y el desarrollo, ante la carencia de voluntad política de las elites civiles para asumir tal responsabilidad, y donde civiles y militares han participado en el juego del poder y se han fortalecido mutuamente.

El proyecto militar de corte homogenizador, es decir, la construcción de una nación mestiza, sufre variaciones a partir de la década del cuarenta (siglo xx) a partir de la doctrina anticomunista, que sumada a la participación de otros agentes de desarrollo (Iglesia, partidos de izquierda, activistas del desarrollo) entre los que se incluyen los propios indígenas como los principales interesados en participar en este proceso, construyen un movimiento indígena con aparente autonomía política y un proyecto étnico que amenaza la propuesta militar de unidad del Estado que cuaja en los inicios de la década del noventa (siglo $\mathrm{xx}$ ).

La consolidación de los distintos segmentos indígenas en torno a un proyecto nacional con matices paraestatales, hace que los militares reorienten la visión del enemigo interno y la política hacia los indios sea resignificada en la aceptación de la diferencia en una suerte de "nacionalismo multicultural” (Selmeski), que implica la cooptación del Movimiento Indígena y la visibilización de variantes ideológicas dentro de éste, orientando su desarrollo dentro de la dinámica institucional de corte estatal, antes que dar prioridad al despliegue de políticas de anulación, a partir de la represión del movimiento indígena, que en Ecuador se erige como el ejemplo emblemático de etnogénesis para la América Latina. Por otro lado, la culminación del proyecto militar de cooptación del movimiento indígena y de sus distintos segmentos ideológicos a la estructura estatal y al conjunto de la nación, tiene su punto máximo en la participación de los indígenas durante la crisis bélica entre Perú y Ecuador ocurrida en 1995 (la denominada guerra del Alto Cenepa). En este enfrentamiento se visualiza a los indígenas de la Amazonía como uno de los puntales del triunfo militar ecuatoriano, que sanciona positivamente su inclusión dentro del imaginario de la nación, es decir: la participación activa de la diversidad étnica en la defensa de la patria.

LA DEFENSA COMO CONCEPCIÓN DE LO MODERNO

La inserción del Ecuador en el sistema capitalista internacional, hasta la primera mitad del siglo xx, debilitó las estructuras agrarias vigentes que perdían funcionalidad frente al sistema económico global en proceso de instauración. Ello implicó desplegar esfuerzos por modernizar las formas básicas de desempeño del Estado y fortalecerlas, al dotarlo del monopolio de la violencia y "un nuevo tipo de ejército" que viabilizara el cambio hacia la modernización (Rouquié, El Estado 64). La formación de tales ejércitos 
demandó, durante las primeras décadas del siglo xx, el arribo a Ecuador de militares chilenos con formación prusiana (1902) y de la Misión Militar Italiana (1922), para modernizar y profesionalizar a los soldados ecuatorianos.

Caracteriza a los militares que reciben esta formación ser antipolíticos y antioligárquicos. Critican a los políticos civiles por su inoperancia en la conducción nacional hacia la modernización, y buscan desmantelar a las oligarquías que encarnan el sistema tradicional en torno a los modelos de civilización nacionalistas de países europeos, donde solo el Estado central y sus elites podían racionalizar el ejercicio de poder orientado al desarrollo progresivo de la civilización. Los ejércitos prusianos (quienes se conciben como el modelo ideal de fuerza militar), se erigieron en guías para la acción política por su lealtad al Estado y la nación, y no a un régimen o gobierno específico (Nunn 33).

En el cuartel, los ejércitos modernos desarrollan una suerte de religión, un sacerdocio laico orientado hacia la defensa de la nación. En Ecuador, la defensa, desde una perspectiva moderna, constituye un esfuerzo colectivo que implica la fusión del ejército con su pueblo (Guerrero 28), y de allí la función social del soldado moderno, quien estudia la patria para conocerla y se capacita para administrarla (Muñoz 181). La "guerra moderna” equivale a mantener a la nación en situación de alerta frente al enemigo: es decir, la nación en armas, a través de la construcción de instituciones dirigidas a la defensa como el servicio militar obligatorio (SMO), que forma el ejército de reserva. Así, los jóvenes que no acepten ser soldados profesionales serían soldados-ciudadanos, dispuestos y formados para la defensa (Rouquié, “Dictadores...”71) y los cuarteles se convierten en escuelas de patriotismo (Loveman xi) para consolidar el poder nacional.

Para lograr los fines mencionados, los militares analizan la realidad geográfica y los factores históricos, sociales y económicos que influyen en la vida y evolución del Estado, que fundamentan la comprensión del mundo (Espinosa 78). Tal concepción alberga un sentido de guerra/realidad, que se encarna en Ecuador, desde su nacimiento a la vida republicana, en la constante amenaza de guerra con Perú, pues la unidad nacional del Ecuador y el modelo de Estado se construyen en torno a la movilización por enfrentamientos con el Perú.

Desde la visión de los militares ecuatorianos, la nación está por construirse, ante la situación de los pueblos a los que se deben: dispersos, desorganizados, en condición de retraso, analfabetos, no contribuyen al mejoramiento de la producción de manera que se propicie la inserción efectiva del país en el mercado internacional. Así, la construcción de la nación moderna, controlada desde el imaginario militar, es la misión que se arbrogan para sí las fuerzas armadas ecuatorianas, proyecto que se inscribe en su concepto de la defensa.

En el siglo xx, las elites ensayan modelos de modernización que implican la participación directa de los indios en los procesos de modernización de la economía, tecnologización de los sistemas productivos y apertura al mercado internacional. El indio es visto como problema para la integración y el progreso (Ortiz). La política de la diferencia que ejercen las elites sobre los indios, define el perfil que adquieren los segundos como elite de poder y las características que toma esta relación de fuerza entre indios y militares. Ello tiene como colofón la organización indígena que se expresa públicamente en los noventa. 
El SERVICIO MILITAR OBLIGATORIO (SMO) COMO ESTRATEGIA DE CIUDADANIZACIÓN

La preparación del ejército de reserva para la guerra es una de las misiones fundacionales de las fuerzas armadas, con cuyo fin se instauró desde 1938 el servicio militar obligatorio. ${ }^{5} \mathrm{Si}$ bien la obligatoriedad de cumplirlo tiene en el plano ideal una vocación universal, muchos de sus programas de entrenamiento, así como los discursos que se generaron a favor de su puesta en marcha, enfatizaron su funcionalidad como instrumento de homogeneización (Chiriboga 611).

Desde la esfera militar, los indios fueron vistos como un problema por su diferencia, incongruente con la nación unitaria; los militares fueron los llamados a "mejorar la raza" (Chiriboga 611), potenciar la participación de los indios en el ejército, de manera que se preparasen para la defensa de una misma nación, lo que equivale a homogeneizarlos, ciudadanizarlos. ${ }^{6}$ Todo ello alimentó formas de concepción de la diferencia que se evidenciaron durante las primeras décadas del siglo xx, en la preocupación de los militares porque los batallones ecuatorianos estaban constituidos por soldados con "taras raciales", sin "virtudes morales", en los que a excepción de pocos individuos, todos los demás constituían una "tropa enana y tarada con debilidades musculares” (Chiriboga 611).

Desde la concepción castrense, el SMO entre los indígenas propiciaría un nuevo tipo de trabajadores: "más conscientes, disciplinados, morales, ordenados y más amantes de la tierra en la que ellos y su familia gozan de bienestar” (Paz 302). Se garantizaba que ocupasen su lugar en la escala jerárquica al permanecer en sus tierras de origen, y se mantuviesen como mano de obra agraria, de regreso a la hacienda, al salir del cuartel (Guerrero 300). Se trataba de adaptar el habitus del indio para integrarlo en un nuevo esquema cultural, sin retirarlo de sus zonas tradicionales de asentamiento, desde donde resultaba funcional.

Desde el punto de vista militar, el SMO constituía una escuela de formación de líderes y ciudadanización en la que los conscriptos aprenderían a "amar a una misma Patria” (Paz 13). Complemento de la escuela para el pueblo, el cuartel los dotaría de buenas costumbres, además de enseñarles a leer y escribir (22).

No interesó en tal proyecto desindianizar al indio en términos fenotípicos sino en cuanto a su adquisición de símbolos comunes ajustados al ideal de la nación y del Estado, interesó compartir con ellos los enemigos y la responsabilidad de la guerra. Fue un esfuerzo de construcción estatal que pretendió sustituir un Estado no equitativo por otro, inspirado en la estructura jerárquica del cuartel: con un orden, donde cada individuo tuviera un sitio en la organización a partir de sus méritos y capacidades individuales, con los indios situados en la base de la pirámide; con posibilidades de ascenso en la jerarquía, pero después de un proceso de mestizaje en los valores nacionales.

\footnotetext{
${ }^{5}$ Pese a que la creación del SMO se había decretado durante la administración alfarista (1902), recién en 1938 comienza a funcionar de manera continua, durante el paso de Enríquez Gallo por el ejecutivo.

${ }^{6}$ Las leyes de la geopolítica contemplan el fomento de la ciudadanía como factor de incremento del poder nacional (Espinosa 79).
} 
EL SIGLO XX TEMPRANO: LOS INDIOS Y UN NUEVO IMAGINARIO DE NACIÓN

Tradicionalmente, las elites han racializado la diferencia, al concebirse a sí mismas como superiores frente a los indígenas por su condición étnica. Tal criterio de inferiorización se proyecta como exclusión, al colocar a los indios en una posición de minoridad, sin capacidad de decisión política propia, carentes de proyecto, débiles ante la manipulación de agentes externos que sí piensan y los pueden utilizar para sus fines.

La hacienda serrana, de raíz colonial, perdió vigencia como sistema de dominación de los indios cuando la producción de la costa pasó a ser más importante por su ligazón con el sistema capitalista internacional. A fines del siglo xix la exportación cacaotera y el comercio de importación posibilitaron la emergencia de una burguesía ávida de poder político para consolidar su influencia como grupo de referencia. Al perder su poder económico y político, la hacienda carecía de facultades de control social directo desde sus fundos sobre los indios, con el consiguiente vaciamiento del discurso tradicional desde el poder.

Con la supresión del tributo indígena (1857) de antecedente colonial, los indios se desligaron de la administración estatal y quedaron bajo la tutela del hacendado, en una condición de propiedad privada. Bajo una lógica de administración de poblaciones, se requería institucionalizar a los indios para controlarlos y garantizar su funcionalidad al sistema; las elites en general, compartieron esta visión y se involucraron en procesos de organización indígena, desde una perspectiva diferenciada que los adscribía espacialmente al campo y los convertía en tributarios de la economía, a través de la producción agraria en sustitución de la hacienda.

La izquierda, desde 1926, incursionó en la organización diferenciada de los indios, con un contenido clasista, al formar la Federación Ecuatoriana de Indios, a partir de sindicatos que se constituyeron al interior de las haciendas a instancias del partido comunista. A inicios de la década del veinte los pensadores del socialismo naciente debatieron sobre la necesidad de entregar tierra a los indígenas, pues se concebía que allí radicaba la solución a esta problemática social. Se la vislumbraba como una fórmula de modernización del agro y como arma de batalla en contra de las oligarquías latifundistas tradicionales, a partir del cambio del tipo de tenencia de tierra que otorgaría derechos a los indígenas.

En esta etapa emerge la acción militar como eje central de cambio, a partir de la política social que aplicó el general Alberto Enríquez Gallo (1937-1938) frente al tema indígena en su paso por el ejecutivo. Como jefe supremo, aglutinó el pensamiento de otros representantes de las elites (los conservadores, los liberales, la izquierda, la iglesia, los activistas del desarrollo, los militares, entre otros) y perfiló los lineamientos de un proyecto nacional de corte militar, construido a partir de la noción de mestizaje cultural y étnico, que se tradujo en políticas integracionistas. Esto persiguió la institucionalización de un Estado débil (véase Paz).

Se construyó una imagen del indio como objeto de reivindicación paternal, o como “peón semiótico” (Muratorio 17), al que ponían como parapeto en su discurso contra sus contrincantes políticos. El socialismo de la época no era considerado una amenaza para el Estado, sino un mecanismo para acelerar su modernización, una vez que los indios eran 
percibidos por las elites como obstáculos para la consecución de sus proyectos de nación: proletarizarlos, ciudadanizarlos, evangelizarlos, integrarlos, fueron términos equivalentes en este contexto (Ortiz).

Durante la jefatura suprema del general Enríquez Gallo se dieron pasos en firme para dotar de un orden al proyecto de Estado militar (homogéneo), al legalizar una forma determinada de organización de los indios con la emisión de la ley de organización y régimen de las comunidades indígenas, que reconocía los derechos a una vida cívica y administrativa de caseríos, barrios, comunidades y parcialidades indígenas, carentes de reconocimiento jurídico hasta entonces. Con el objeto de regular la migración campesina a las ciudades, Enríquez auspició la emisión de las leyes de control de trabajo y desocupación y la de cooperativas (Burbano 41).

En los primeros años de su promulgación, estas leyes quedaron en el papel. Sin embargo, su aplicabilidad se evidencia con el avance en el proceso de reforma agraria a partir de la década de los sesenta (siglo xx). Estas formas organizativas retomaron modelos anteriores, el cabildo y la comuna, que reajustándose al sistema vigente para favorecer la modernización nacional, se reacomodaron a la circunstancia, sin perder su esencia colonial que excluyó a los indios por su condición étnica. ${ }^{7}$

\section{LA CIUDADANIZACIÓN DE LA MANO DE OBRA AGRARIA}

La educación es, por antonomasia, instrumento de transferencia de la cultura dominante, y desde la perspectiva militar de conformación de la nación unitaria, estrategia indispensable para la integración nacional, para la incorporación del "indio y el montubio a la vida civilizada”, con el consiguiente elevamiento de su condición económica (Paz 142). Los militares la acogieron como medio de adquisición de ciudadanía. Para efectivizar esta idea entre los indígenas, Enríquez Gallo decretó que "todo hacendado, propietario, arrendatario o patrón rural [...] deberá dar preparación elemental a sus trabajadores del campo, de edades entre los ocho a veintiún años” (Burbano 41). La ley de educación primaria y secundaria, de mayo de 1938, dispuso que los propietarios de predios agrícolas con avalúo entre los cien mil y quinientos mil sucres, ${ }^{8}$ pagasen un impuesto anual de seiscientos sucres destinados a la "creación y mantenimiento de escuelas rurales" (Burbano 41). Se preveía la enseñanza del quechua para los futuros maestros de aquellas escuelas. Se buscaba mantener ciertos elementos culturales del mundo indígena, y cambiar otros para que la homogeneización fuese funcional, como un primer paso para la integración, pues a partir de su vinculación con el Estado y el orgullo de pertenecer a la nación las diferencias étnicas desaparecerían por sí solas. La educación forjaría una ideología nacional, y provocaría cambios en el mundo indígena, de manera que de una

\footnotetext{
${ }^{7}$ Enríquez es reconocido con orgullo, hasta la actualidad, por los órganos de difusión de las fuerzas armadas, por su defensa de los derechos humanos y sus leyes a favor de los trabajadores (www.fuerzasarmadasecuador.org.ec). El parlamento de los pueblos del Ecuador se reconoce heredero de la "historia de dignidad del Ecuador", y se constituye como seguidor del camino abierto por Enríquez y otros ciudadanos notables (http//:abyayala.nativeweb.org.ec).

${ }^{8}$ La moneda oficial en Ecuador fue el sucre hasta 1998, cuando se aplica el mecanismo de dolarización de la economía.
} 
cosmovisión indígena -constituida por su pasado aborigen y por los procesos coloniales de dominación y evangelización-, pasasen a otra de Estado-visión, de la ecuatorianidad.

La modernización que proponen los militares durante la primera mitad del siglo xx en el tema indígena, busca una integración que tolera la diferencia en contraste con la propuesta del siglo anterior, que, entre otras limitantes para los indios, prohibía la entrada de los niños con sus vestimentas tradicionales en las escuelas de los Hermanos Cristianos. ${ }^{9}$ En la década de los treinta son otros los contenidos del proyecto modernizador, con trazos de un multiculturalismo en el imaginario militar, atravesado por los sesgos propios de su época.

LA OPTIMIZACIÓN DE LA PRODUCCIÓN Y LAS CONDICIONES DE LA MANO DE OBRA AGRARIA

Al expedirse el Código del Trabajo (1938), se fijaron el jornal del huasipunguero; ${ }^{10}$ la duración y los descansos de su jornada laboral en el campo; y sus derechos y los de su familia al agua, leña, caza, pesca, a los pastos para su ganado (Burbano 41). De esta manera, a la vez que se protegía la productividad, se garantizaban mejores condiciones para la fuerza de trabajo que motivasen su estadía en el agro y optimizaran sus capacidades. Los militares vieron la importancia de otorgar crédito a los trabajadores del campo para su inversión en el mejoramiento de cultivos y la introducción de nuevas tecnologías (Paz 43).

Progreso y desarrollo son paradigmas de la construcción nacional y, en el ethos militar, son fuentes del poder de la nación con un enfoque que privilegia lo tecnológico como vía de modernización. Al permitir la comunicación interna de las poblaciones, las vías constituyen medios de progreso y de “afirmación de la ecuatorianidad” (Serrano 30). ${ }^{11}$ Las carreteras forman parte del proyecto militar, por lo cual Enríquez Gallo estableció la Escuela de Ingenieros del Ejército con maestros italianos y profesores de la Escuela Politécnica Nacional. ${ }^{12}$ A más de integrar a la nación las vías facilitarían el control social por parte de las fuerzas del orden y el transporte de la producción desde zonas apartadas a otros espacios de comercialización.

Luego de la derrota militar ecuatoriana frente a Perú, en el marco de la guerra de 1941, se intensificó el interés del ejército por construir vías en la Amazonía para resguardar las

\footnotetext{
${ }^{9}$ Gabriel García Moreno (presidente entre 1861 y 1875) trajo a los Hermanos Cristianos (católicos), quienes tuvieron la responsabilidad de la educación; ellos instauraron una estricta metodología educativa que se difundió en el ámbito nacional. Esta orden, en la misma época, dirigió la escuela militar (Ortiz).

${ }^{10}$ Este sistema consistía en la asignación al interior de sus predios, por parte del hacendado a los trabajadores, de un pedazo de tierra o huasipungo en el que podían vivir con sus familias en una relación de sujeción frente a la hacienda.

${ }^{11}$ Otros momentos de modernización como los períodos garciano (1861-1875) y alfarista (18951911) habían visto también esta dimensión al auspiciar la construcción del ferrocarril, que se concluye en 1908 en el tramo que une Guayaquil y Quito, el puerto principal y la capital del país. ${ }^{12}$ Institución de educación superior localizada en Quito, con alto prestigio y nivel académico, fundada por García Moreno. En la época mencionada, la institución mantenía una plana de profesores ecuatorianos y de origen alemán y francés.
} 
zonas de frontera. Habida cuenta del carácter estratégico de la región, interesaba resguardarla debido a los recursos naturales que alberga. En 1946, el cuerpo de ingenieros del ejército construyó la vía Baños-Puyo ${ }^{13}$ acción que buscaba acortar distancias, facilitar la explotación de las riquezas naturales y adquirir una "visión clara y precisa de que el Ecuador en la organización de América es uno, fuerte e indivisible”; otro de sus fines fue el de "introducir la corriente civilizadora y progresista en el oriente ecuatoriano [Amazonía ecuatoriana]” (Serrano 2).

Desde una lectura de guerra/realidad, estas fueron las medidas defensivas que los militares tomaron frente al otro, visto como amenaza a su proyecto moderno de nación, ante lo arcaico de sus condiciones, que lo incapacitaban para contribuir con la consolidación del sistema económico en ciernes.

\section{INTEGRACIÓN, SEGURIDAD Y DESARROLLO}

Desde la década de los cincuenta, culminada la segunda guerra mundial, los contextos nacional e internacional se enrumbaron hacia la modernización. Las carencias tecnológicas, la falta de educación de la población, su estado de retraso y pobreza, y la ausencia de una racionalidad acumulativa en el manejo de la producción agrícola constituían serias limitaciones a la transición del Ecuador hacia prácticas capitalistas que colocasen al país y su gente a tono con las demandas del orden global.

El triunfo de la revolución cubana (1959) provocó la adopción por parte de Estados Unidos de políticas de seguridad hemisférica, con el fin de prevenir la aparición de focos comunistas. Desde el centro se emitieron fuertes aportes económicos para la aplicación de modelos reformistas a través de organismos de desarrollo o ayudas directas. Dado el tinte defensivo de estas políticas, las fuerzas armadas de esos países fueron el brazo ejecutor de las tareas del desarrollo, involucradas en la doctrina de seguridad nacional, como fórmula para preservar la integridad de la nación al "neutralizar, contrarrestar o poner fin a la amenaza de la subversión” (Aulestia 10). Desde esta perspectiva de la defensa, el subdesarrollo constituyó el enemigo interno; seguridad y desarrollo adquirieron un significado unívoco y se condicionaron entre sí. ${ }^{14}$

En Ecuador, desde 1956 hasta fines de los setenta, se asentó la Misión Andina para el Ecuador (MAE) con apoyo de Naciones Unidas. Con el enfoque de desarrollo de la comunidad, se fortaleció la capacidad de participación de los productores del campo, la organización comunitaria y la formación de líderes; ${ }^{15}$ entrenó a sus beneficiarios en aplicación de la ley de comunas (emitida por el general Enríquez en 1938). Se introdujeron elementos tecnológicos e ideológicos para homogeneizar/civilizar a las comunidades indígenas e inducirlas en las lógicas del mercado y la industrialización.

\footnotetext{
${ }^{13}$ Vía de entrada desde la sierra hacia la Amazonía.

${ }^{14} \mathrm{En}$ el cono sur los militares fueron explícitos en adoptar al comunismo como enemigo interno, y aplicaron políticas represivas en contra de la población. En Ecuador las fuerzas armadas ponen énfasis en el desarrollo, lo que varía sustancialmente la utilización de prácticas represivas.

${ }^{15}$ Algunos de los dirigentes campesinos formados bajo estos auspicios encabezaron posteriormente los procesos de consolidación del movimiento indígena en la sierra (Bretón).
} 
Éste constituyó un modelo agresivo de modernización que comprometió la defensa hemisférica orquestada desde Estados Unidos, al ver este país amenazado su poder por la potencial expansión del comunismo. Pero, a su vez, empataba con la necesidad sentida por las elites locales de fortalecer un Estado nacional poco cohesionado en Ecuador. Estas veían al indígena como fuente del estancamiento nacional, lo cual los llevó a avalar tales estrategias de integración, que a más de todo, vinieron con recursos propios. En esta medida, el anticomunismo constituyó una justificación de las elites civiles y militares para solucionar los problemas de construcción de identidad y de ciudadanía, y confirió a las fuerzas armadas un marco de acción política legitimado internacionalmente.

El esquema de institucionalización que propuso esta estrategia coincidió además con las formas de integración aprobadas por los militares, por su funcionamiento estructurado y planificado. En opinión de un oficial del ejército, la MAE buscaba sacudir a los indios del "marasmo y conformismo en que vivían, despertar la conciencia individual y colectiva a favor del desarrollo y su posibilidad de opinar con criterio propio” (Gudiño 20). La MAE preparó instructores, oficiales y tropa para capacitar a los conscriptos en la formación de líderes y asesoró a los militares en el diagnóstico de las necesidades de las comunidades (Pazmiño 33).

Desde las fuerzas armadas se institucionalizó la acción cívica ${ }^{16}$ que a nombre de la contención al comunismo, intervino en las zonas de ausentismo estatal. Los principios del SMO se proyectaron fuera del cuartel con la conscripción agraria militar ecuatoriana para defender el frente externo y consolidar el frente interno. Se entregaron parcelas de tierra a colonos y sus familias en la Amazonía, se los entrenó en el uso de las armas, se implantaron así fronteras vivas. Como estrategia de defensa del frente interno, se los ciudadanizó a través de la educación y técnicas agrícolas.

La Alianza para el Progreso, emblema de la lucha anticomunista dentro de la administración Kennedy (EE.UU.), preparó a la población para la reforma agraria, para aumentar los niveles de productividad y eficiencia entre los trabajadores agrícolas, eliminar formas tradicionales de tenencia de la tierra y liberar mano de obra para la industria (Varas y Bustamante 63). En 1964, en el contexto de una junta militar (19631966) y con apoyo de las elites civiles se emitió la primera ley de reforma agraria. ${ }^{17}$ La junta tenía la misión de modernizar al país, redistribuir la tenencia de la tierra e introducir a los trabajadores en procesos de industrialización, bajo los principios de la planificación para el desarrollo; sin embargo, a primera vista, su limitación fue que favoreció a las oligarquías.

Un nuevo momento de intervención militar dictatorial se ubicó entre 1972 y 1976, en la antesala del boom petrolero. Los militares justificaron su presencia en el poder por la falta de interés de la clase política en dar una respuesta a los temas petroleros y de integración andina (GNR 4). El general Guillermo Rodríguez Lara ${ }^{18}$ encabezó el Gobierno

\footnotetext{
${ }^{16}$ En 1962 se instituye la Dirección de Acción Cívica de las fuerzas armadas.

${ }^{17}$ Esta fue una primera ley de reforma agraria (1964). Se emitió otra posteriormente, en 1973.

${ }^{18}$ El plan de acción de aquella dictadura lo estructuraron miembros del ala progresista de la marina, en colaboración con una tecnocracia naciente.
} 
Nacionalista Revolucionario que aspiraba a invertir el producto del petróleo en el desarrollo industrial con una política de sustitución de importaciones.

Esta administración mantuvo el proyecto militar integracionista basado en el mestizaje y la homogeneización (véase Rodríguez Lara 18). Se dotó a los indios de la categoría de campesinos con lo cual se disimularon los problemas de la diferencia étnica. El gobierno militar emitió una nueva ley de reforma agraria (1973) para introducirlos en la economía de mercado y se pensó en el SMO como un espacio para el entrenamiento de la mano de obra agrícola (Gobierno Nacionalista Revolucionario 7). La entrega de tierras se condicionó a la organización de sus receptores en cooperativas agrícolas (organizaciones de primer grado). ${ }^{19}$

Petróleo, colonización e integración nacional

El proceso de colonización amazónica provocado por el boom petrolero, y liderado por los militares, invisibilizó la presencia de grupos tribales en la selva, al concederse tierras habitadas considerándolas como baldías. Es en este contexto cuando los militares entraron a interactuar con los grupos indígenas amazónicos, una vez que éstos ya habían atravesado experiencias civilizatorias, a través de la evangelización a instancias de la iglesia católica y confesiones cristianas evangélicas, como el Instituto Lingüístico de Verano.

Con fondos petroleros se crearon entidades estatales destinadas a respaldar la producción, la mano de obra agrícola y la estadía de los indios en el campo, en especial a través del crédito; sin embargo, la modernización que se propició a través de los recursos petroleros fortaleció el proceso de urbanización, entre tanto los cambios en el agro provocaron una situación de crisis que atrajo la migración a la ciudad. Un amplio sector de los indios inmigrantes se incorporó a la industria de la construcción y otro al comercio y a la venta de servicios. ${ }^{20}$

La década de los setenta llegó a su fin en un momento de transición a la democracia. De 1976 a 1979 gobernó un nuevo triunvirato militar. En ese contexto, se provocaron situaciones de violencia frente a los trabajadores agrícolas; ejemplo emblemático fue el caso del ingenio azucarero AZTRA, en la costa, donde en respuesta a la protesta murió un número nunca especificado de zafreros, indígenas serranos, mano de obra itinerante. Se decretó la emergencia. Sin embargo, la participación de efectivos militares en la represión fue mínima, función que el triunvirato, que cumplía el rol de instrumento de control político en la etapa de transición, delegó a la Policía Civil Nacional, que de cierto modo lava la imagen de los militares.

A fines de los setenta se avizoraba una situación de crisis para Ecuador y la subregión. En ese contexto, los militares dieron paso a la entrega del poder a los civiles, no sin antes

\footnotetext{
${ }^{19}$ En las que luego se basa la conformación de las organizaciones indígenas de alcance nacional como la Confederación de Nacionalidades Indígenas del Ecuador (CONAIE).

${ }^{20}$ Durante las épocas colonial y republicana los indígenas suplieron las necesidades de mano de obra para la construcción como peones y albañiles; sin embargo, en el boom de la construcción, durante el período en mención, este oficio amplía la necesidad de personas dedicadas a él.
} 
asegurarse el acceso a posiciones clave en el control de las áreas estratégicas de la economía, ${ }^{21}$ a nombre de la defensa de la integridad nacional; en este contexto se registró además el crecimiento de la deuda externa. La transición a la democracia atrajo una situación crítica dado el reacomodo de las fuerzas políticas que atribuyeron a la dictadura la causa de los problemas existentes. Ello bajó el prestigio de los militares, concomitantemente en 1978 al asesinato de un candidato presidencial, ${ }^{22}$ del cual fue responsable el ministro de Gobierno del Triunvirato (general Bolívar Jarrín Cahueñas), en un afán por orientar y condicionar el futuro político del país luego de la dictadura y escarmentar a quienes cuestionaran al régimen saliente.

El período democrático arrancó con un nuevo conflicto armado frente a Perú, la Guerra de Paquisha (1981). Este episodio bélico se constituyó en derrota militar; no obstante, el enfrentamiento militar logró convocar a todas las fuerzas políticas y sociales en torno a la defensa de la patria y los militares se constituyeron en emblema de la nacionalidad, a pesar del deterioro sufrido durante la época de la dictadura y en los sucesos acaecidos en la transición. Como medida inmediata al conflicto, las fuerzas armadas intensificaron su presencia en la frontera sur con una fusión entre defensa y desarrollo que profundizó la relación de interdependencia asimétrica entre indios y militares en esa región. En los ochenta, los recursos estatales y la ayuda internacional para el desarrollo se canalizaron entre los indios de la sierra, a través de una gama de activistas del sector civil de corte tecnocrático o evangelizador.

LOS TRASTORNOS DE FIN DE SIGLO

Con el fin de la guerra fría (1989), la última década del siglo inició con una amenaza menos. Las políticas anticomunistas, justificación de la intervención militar en el desarrollo, desaparecieron del horizonte defensivo. Sin embargo, en Ecuador, el desarrollo no perdió peso como misión consubstancial de las fuerzas armadas y otras amenazas hicieron su aparición en escena. No obstante la organización indígena se erige como una amenaza que representa una suerte de continuidad histórica, con nuevos matices.

La consolidación de la organización indígena ecuatoriana se dejó sentir hacia 1986 al conformarse la CONAIE, que aglutinó a distintas asociaciones regionales. ${ }^{23}$ Éstas se conformaron a partir de las organizaciones de primer grado, ${ }^{24}$ en cuya génesis se evidenciaron las prácticas de institucionalización indígena de las que se sirvieron las elites en la construcción de su proyecto homogéneo de nación, desde inicios del siglo xx. Éstas adquirieron una tendencia etnicista a lo largo del proceso de consolidación de la

\footnotetext{
${ }^{21}$ Petróleo, electricidad, telecomunicaciones, industria, etc. (Dirección de Industrias del Ejército 5). ${ }^{22}$ Abdón Calderón Muñoz, candidato por el Frente Radical Alfarista fue asesinado por sicarios (civiles) contratados con dineros públicos por una orden dada por el ministro de Gobierno general Jarrín Cahueñas.

${ }^{23}$ Entre éstas sobresalen ECUARUNARI en la sierra, creada en 1973 a instancias de la iglesia progresista y la CONFENIAE que aglutina a las nacionalidades amazónicas y se crea en 1981 bajo los auspicios de la misión salesiana, entre los shuar.

${ }^{24}$ Comunas, cabildos, cooperativas, agrupaciones de productores, entre las que se cuentan las que se activaron en período colonial.
} 
organización y dada la segregación de la que fueron objeto justamente por la pertenencia étnica de sus integrantes.

En junio de 1990 (siglo xx) los indios organizados en la CONAIE paralizaron el país ${ }^{25}$ en demanda de acceso a la tierra para la ampliación de sus unidades domésticas, lo que también implicó el reconocimiento de sus derechos, sus nacionalidades y la defensa de la naturaleza. El repertorio de la protesta indígena no varió sustancialmente durante toda la década, pero dio relevancia paulatina a la participación de los indios.

En 1992, el respaldo internacional a la causa india se dejó sentir, cuando se conmemoran los quinientos años de la colonización europea. Estas acciones involucraron también el incremento de la presencia de organismos internacionales de cooperación que pusieron mayor atención a las demandas indígenas, como fórmulas de desarrollo. Los indios se acogieron al convenio 169 de la OIT sobre los derechos de los pueblos indígenas y tribales. En 1998, se emitió una nueva carta constitucional en que se reconoció al Estado ecuatoriano como pluricultural y multiétnico.

Si bien la organización indígena fue bien recibida por los militares, ${ }^{26}$ el discurso multinacional que esgrimieron los indígenas al aparecer en la escena pública provocó alarma ${ }^{27}$ en un inicio, ${ }^{28}$ pues el discurso ponía en peligro su proyecto unitarista de nación homogénea y, sobre todo, porque amenazaba la estabilidad militar, al ser la nación única e indivisible. Los temores se obviaron en el camino, cuando los indios depuraron su concepto sobre las “nacionalidades”, que resultó coincidente con el proyecto multicultural de las elites (Ortiz).

Para reprimir esta amenaza los militares emplearon las formas simbólicas de contención del comunismo, ya no como acción cívica, sino como apoyo al desarrollo, con énfasis en la formación de "soldados agrarios” (Selmeski, "Warriors...” 5). Se establecieron relaciones institucionales entre indios y militares en las que la dirigencia indígena pasó a ser la interlocutora de las autoridades militares (Ministerio de Defensa Nacional 70).

En 1998, se firmó el tratado de paz con Perú y con ello se puso fin a una de las narrativas que históricamente justificaron las tareas defensivas de los militares ecuatorianos. Éste constituyó un motivo más para que las fuerzas armadas reorientaran sus energías bélicas a la defensa del frente interno. El apoyo al desarrollo como estrategia de defensa estrechó la relación entre indios y militares. La organización indígena se fortaleció con la

\footnotetext{
${ }^{25}$ El levantamiento indígena de junio de 1990 paralizó Quito por tres días. Contó con mayor participación de los indígenas de Cotopaxi, Tungurahua, Chimborazo, Bolívar, Cañar y Loja y levantó las simpatías de segmentos de la población blanco-mestiza y el resquemor de otros integrantes de este segmento poblacional.

${ }^{26}$ En la medida en que posibilitaba la institucionalización del sector con fines de control de la mano de obra. Es decidor que en el contexto de la dictadura de Rodríguez Lara (1973) se fundara la Confederación de Organizaciones Indígenas de la Sierra ECUARUNARI.

${ }^{27}$ La propuesta multinacional que ya había sido mencionada por el presidente Borja (1988) y había motivado las demandas de cumplimiento de tal posición por los indígenas, levanta críticas entre los militares (Fiallo 82).

${ }^{28}$ La propuesta multinacional que ya había sido mencionada por el presidente Borja (1988) y había motivado las demandas de cumplimiento de tal posición por los indígenas, levanta críticas entre los militares (Fiallo 82).
} 
anuencia de los militares, pero el proceso propio de los indígenas como actores políticos consolidados, sumado a la influencia de la iglesia, ecologistas, apoyos internacionales y los grupos de izquierda, dotan de características singulares a la organización india. De esta manera, esta toma un giro inesperado con las aspiraciones políticas de los indios.

LA DEFENSA DE LA SOBERANÍA: UN ESPACIO PRIVILEGIADO PARA LOS SOLDADOS INDIOS

La guerra del Cenepa contra Perú (1995) contó entre sus filas a soldados indígenas amazónicos unidos en el frente de batalla contra el enemigo común. Los indígenas defendían sus propios intereses que no se divorciaban de los de la nación ecuatoriana. ${ }^{29}$ Esta muestra de integración, de fuerte carga simbólica, avalaba la presencia de los indios en la frontera como actores políticos, así se fortaleció el movimiento indígena y su reconocimiento internacional. A raíz de tales sucesos se conformó Pachakutik (1996) en estrecha vinculación con la CONAIE, que permitió la participación en las elecciones de los indios a través de su partido propio que incluía dentro de sus cuadros a un segmento de políticos de origen blanco-mestizo. En lo posterior, bajó el perfil de los indios organizados como amenaza para los militares, su participación en la política formal los colocó al mismo nivel.

Este evento ponía al descubierto, por otro lado, un tratamiento distinto de los militares entre los indios amazónicos y los serranos que respondió a un imaginario de "nacionalismo multicultural” (Selmeski, "Warriors...” 3) ${ }^{30}$ Los primeros recibieron la responsabilidad de las armas por su adscripción espacial al campo de batalla -el frente externo; los segundos defendieron a la nación desde el trabajo agrícola bajo el lema "no sólo es soldado el que lleva el arma al brazo en el campo de batalla, sino quien hinca el arado en el suelo nacional para hacer Patria” (Guevara 129).

En la conformación de Pachakutik se pensaba que la dirigencia blanco-mestiza, con experiencia en la política de tipo electoral, lideraría la organización. Sin embargo, en el transcurso de la experiencia organizativa los dirigentes indígenas fueron orillando sistemáticamente a los blanco-mestizos a posiciones jerárquicas sin importancia o fuera de la organización. A pesar del control de los dirigentes indígenas, esta organización se proyecta como un modelo multicultural, por lo cual cuentan con un grupo de blancomestizos que sirven de puente con otras organizaciones políticas de tendencia de izquierda. ${ }^{31}$

\footnotetext{
${ }^{29}$ Las tierras de habitación shuar habían sido las más afectadas históricamente por el conflicto limítrofe entre ambos países.

30 "Las semillas del nacionalismo multicultural fueron detectadas al interior de los cuarteles antes que en muchos otros segmentos de la sociedad ecuatoriana o de las entidades estatales” (Selmeski, "Warriors... 4).

${ }^{31}$ Pachacutik como minoría política busca acumular capital político a partir de las alianzas con otras organizaciones y explotan el efecto simbólico que genera "el levantamiento indígena” como forma de presión política en las distintas instancias de control estatal y en el imaginario de la población blanco mestiza que por un lado teme al indio y por otro lado le brinda un apoyo parcial.
} 
INESTABILIDAD POLÍTICA Y EL GOLPE MILITAR DE 2000

A fines del siglo xx el Ecuador vivía una de las mayores crisis de su historia. Comprometía todos los aspectos de la vida nacional y se desató con fuerza con la caída del presidente Abdala Bucaram (1997). ${ }^{32}$ Para los militares, con Bucaram peligraba la estabilidad de la nación por sus prácticas populistas y su discurso frente a Perú, que planteaba la política del perdón que tampoco fue bien recibido por el resto de elites de poder. En este evento participaron entre la sociedad civil los indios organizados, y se potenció el tropo de la bravura indígena, lo que fortaleció a su movimiento con el expreso impulso de la cúpula militar y sus agencias de inteligencia. ${ }^{33}$

La crisis de fin de siglo entraba en sus peores momentos durante el gobierno de Jamil Mahuad (1998-2000), con la caída de las estructuras financieras por la corrupción y complicidad del gobierno. Tal situación afectó corporativamente a las fuerzas armadas, que vivían momentos críticos de reacomodo institucional una vez superada la etapa de guerra contra Perú, hecho que vaciaba su discurso, pues se cuestionaba la razón de ser de las fuerzas armadas.

La firma de la paz afectaba seriamente el presupuesto que hasta entonces se había destinado a la defensa, más aún si se toma en cuenta la política neoliberal de servicio a la deuda externa preponderante en aquellos momentos. Había inconformidad en las filas militares desprendida de los manejos económicos del régimen que desembocaron en el colapso del sistema financiero nacional. Los militares, sumados al movimiento indígena y a los movimientos sociales buscaron estrategias de desestabilización política.

En la coyuntura previa al 21 de enero de 2000, ciertos miembros de las fuerzas armadas se envolvieron en acciones conspirativas: “el Comandante del Ejército, general [Telmo] Sandoval, se convirtió en el principal conspirador, había estado en contacto con los indígenas, con los choferes, con la gente de las cámaras, hablaba de destituir los poderes del Estado" (general Gallardo, entrevista de noviembre de 2003); ${ }^{34}$ el general Carlos Mendoza (jefe del comando conjunto de las fuerzas armadas =COMACO) coordinaba con Sandoval los distintos movimientos del alto mando y conocía de las evoluciones de los coroneles, alumnos de la Academia de Guerra y oficiales subalternos alumnos de la Escuela Politécnica del Ejército, quienes iban a protagonizar la asonada del 21 de enero.

La convulsión social del 21 de enero de 2000 protagonizada por indígenas, movimientos sociales y el grupo de coroneles es catalizada con la conformación de un triunvirato conformado por dos civiles y un militar, conformado por Antonio Vargas (presidente de

\footnotetext{
${ }^{32} \mathrm{El}$ populismo, particularmente el que pone en práctica la familia Bucaram, fue combatido por los militares a lo largo de todo el siglo xx. Cuando Abdalá Bucaram resulta electo presidente de Ecuador fue rechazado por buena parte de las elites y por algunos sectores de la población, especialmente en Quito, y entre los indígenas. En febrero de 1997 Bucaram fue derrocado con el apoyo de las fuerzas armadas, evento que fue disfrazado por el congreso nacional con la figura de la destitución debido a su "inestabilidad mental".

${ }^{33}$ Esta información fue entregada por un coronel en servicio pasivo, integrante de los movimientos sociales, que prefiere guardar el anonimato.

${ }^{34}$ En esa coyuntura, Gallardo era ministro de defensa.
} 
la CONAIE); Carlos Solórzano Constantine (ex presidente de la Corte Suprema de Justicia), y el general Carlos Sandoval (quien fungía de jefe del COMACO). Este triunvirato duró aproximadamente cuatro horas hasta la madrugada del 22 de enero y fue liderado por Mendoza quien logró diluir el golpe de Estado por la falta de legitimidad que este tuvo entre las elites (políticas y económicas), oposición de los medios de comunicación y que, a pesar de la efervescencia de un segmento ciudadano, principalmente localizado en Quito (capital del Ecuador), no caló en el imaginario de la mayoría de la población.

Mendoza y Sandoval influirán en la mañana del 22 de enero, para que el vicepresidente del presidente Mahuad, Gustavo Noboa, asumiera el poder en lugar del triunvirato promovido por los movimientos sociales y el coronel Lucio Gutiérrez. El general Carlos Mendoza garantizó la lealtad de las distintas ramas de las fuerzas armadas al nuevo gobierno que fue legitimado en el poder por el congreso nacional por un nuevo eufemismo jurídico, pues se acusó a Mahuad de abandono del cargo. Lo cierto es que el gobierno perdió piso después que el COMACO retiró el apoyo al presidente constitucional en funciones.

El alto mando militar, representado por los militares mencionados, utilizó a los coroneles descontentos por la situación económica política para garantizar su statu quo, deteriorado por la crisis económica del país y la crisis institucional, desprendida de la firma de la paz con el Perú. El coronel Lucio Gutiérrez, la cabeza más visible de la asonada, cumplió con el objetivo de destituir a Mahuad por sus aparentes actos de corrupción y causante de la crisis del sistema financiero del Ecuador, justificación esgrimida por los militares para dar el golpe. La mano invisible de la cúpula militar, especialmente de la fuerza teerrestre y sus servicios de inteligencia precedieron y presidieron el proceso del golpe del Estado con la anuencia de las elites civiles opuestas a Mahuad. Mendoza y Sandoval fueron condecorados por el flamante presidente Noboa por sus servicios al país y por haber sacrificado su carrera militar por los intereses nacionales.

LA HISTORIA SE REPITE

Gutiérrez fue colocado en disponibilidad en espera de las sanciones militares. Después de una amnistía dada por el congreso conformó su propio partido político en unión con otros militares que participaron el 21 de enero, que se denominó Sociedad Patriótica Veintiuno de Enero (Lista 3). En las elecciones del 2002, Sociedad Patriótica entró en alianza con Pachakutik (Alianza 3-18) y alcanzó la presidencia de la república, poco después, se evidenciaría la cooptación de la que fue objeto el proyecto indígena; cuando los indios y sus allegados rompieron la alianza y deslindaron responsabilidades con el gobierno de Gutiérrez, que utilizó la simpatía que provocara su propuesta entre los electores para, una vez en el gobierno, anular su poder de decisión.

Los supuestos actos de corrupción cometidos por funcionarios del gobierno del coronel Gutiérrez, la desviación de las promesas de campaña y el perfil incongruente de sus alianzas políticas fueron las causas que precipitaron su caída del poder. Esta suma de circunstancias da paso a las protestas ciudadanas de abril en Quito (13 al 20 de abril de 2005), que condujeron a la destitución de Gutiérrez, lo que da cuenta de una profunda 
crisis del régimen político ecuatoriano, que cuestiona el modelo de Estado vigente, el papel de las elites políticas (civiles y militares)

Gutiérrez en su acción política de carácter público, que se inicia después del golpe del 21, asume las reglas de juego electorales dadas en el marco jurídico ecuatoriano. De esta manera, incorpora formalmente, elementos de carácter inédito en el Ecuador: 1) la visión de la política y del Estado construido con base en los principios y dogmas aprendidos en las escuelas militares y las academias de guerra; 2) la información acumulada en los servicios de inteligencia militar sobre el proceso político y social, y los distintos actores allí insertos; 3) las prácticas políticas normalmente aceptadas en la cultura política ecuatoriana, combinadas con las estrategias de guerra sicológica (información-desinformación) dadas en la doctrina militar; y, iv) canaliza para su beneficio el sentimiento de desconfianza de la población en las instituciones de alcance nacional. La combinación de estos elementos da como resultado la elección de Lucio Gutiérrez como presidente constitucional con una votación altamente representativa en todas las regiones del Ecuador.

La CONAIE, actor gravitante en la política ecuatoriana desde 1997, se debilitó y su representatividad y credibilidad políticas se erosionaron en el espectro nacional al evidenciar fisuras internas producto de la diversidad ideológica y de intereses que se desarrollan a su interior. Los militares en servicio pasivo, la cúpula militar en funciones durante el gobierno de Lucio Gutiérrez y los indígenas vinculados con esa administración pública (o beneficiados de ella) rompieron la aparente unidad del movimiento indígena basado en esencialismos étnicos, pues evidenciaron que los indígenas no actuaban en contra del Estado, sino que se desenvolvieron en función de las reglas de la cultura política ecuatoriana.

\section{REFLEXIÓN FINAL}

La integración indígena en Ecuador entra en la lógica del proceso de modernización nacional orquestado por las elites con el impulso de las fuerzas armadas, como las primeras interesadas en consolidar su proyecto político enfocado en fortalecer al Estado y construir la nación unitaria y homogénea.

Este modelo de nación mantiene un orden jerárquico que reproduce en su interior la estructura institucional de las fuerzas armadas. Los indios, en ese orden, ocupan la base de la pirámide y se les adjudica como responsabilidad la producción agrícola en la sierra, entre tanto en la Amazonía se les encarga enfrentar al enemigo externo, por la localización de sus comunidades en las zonas de frontera; ello demarca una construcción multicultural de la nación, capaz de integrar la diversidad que caracteriza al Ecuador que, de no darle una organicidad desde la lógica defensiva, atenta contra la integridad nacional.

Las fuerzas armadas ecuatorianas no se constituyen como ente represivo porque fueron orientadas más bien a la defensa de las fronteras, ante la constante amenaza de guerra en la frontera sur. Frente a los indios, adoptan medidas disuasivas y preventivas entre las que se inscriben sus políticas integracionistas. En el caso ecuatoriano, no se dan masacres hacia los indios porque son útiles a los modelos de desarrollo que se adoptan en 
los distintos momentos de la historia y la función represiva se delega a la Policía Civil Nacional.

El modelo de integración que se aplica hacia los indios en Ecuador, sostiene una política frente a la diferencia que se caracteriza por la exclusión dada por su condición étnica y se acoge a una propuesta colonialista que no es mal vista desde el sector indígena, cuando utiliza el derecho a la diferencia como bandera de lucha, es decir que los indios adoptan el modelo impuesto y lo vuelven funcional a sus requerimientos.

El 21 de enero de 2000 es un episodio de cooptación del movimiento indígena de parte de un sector de militares que ve peligrar su estatus y sus intereses corporativos. A su vez, utilizan a los indios y rompen su unidad como movimiento político con una propuesta alternativa, propuesta que no deja de mantener los sesgos de la política formal, que a fin de cuentas, había sido su escuela de formación.

La cúpula militar evidencia crisis política interna que es el reflejo de las crisis de las elites civiles. Las fuerzas armadas basadas en dogmas de acción que apuntan a mantener el statu quo dentro de un modelo de Estado que se construyó en relación con el conflicto de límites con el Perú y que todavía no acierta a definir y resignificar su papel en un contexto social y político de carácter heterogéneo, donde los Objetivos Nacionales Permanentes son de libre interpretación de la cúpula militar.

Bibliografía

Asamblea Nacional Constituyente. Constitución Política de la República del Ecuador. Quito: s/e., 1998.

Aulestia, Víctor. “Aspectos generales de la Seguridad Nacional”. Revista de las fuerzas armadas 38 (Quito, 1969): 9-18.

Bretón, Víctor. Cooperación al desarrolloy demandas étnicas en los Andes Ecuatorianos. Quito: FLACSO, 2001.

Burbano, Luis. “Las fuerzas armadas y la problemática indígena en el Ecuador”. Quito: IAEN, 1991.

Bustamante, Fernando. “Tensiones en la relación civil-militar en el Ecuador del siglo XXI”. Univérsitas 3 (Quito, set. 2003): 7-27

Buzan, Barry. People, States, and Fear. An Agenda for Internacional Security Studies in the Post-Cold War Era. Boulder: L. Rienner, 1991.

Coral Patiño, Héctor. Vida y obra del Señor General Alberto Enríquez Gallo. Quito: Banco Central del Ecuador, 1988.

Chiriboga, Leonardo. El problema del indio examinado desde el punto de vista de la organización militar. Quito: Ministerio de Gobierno, 1939.

Eco, Umberto. Seis paseos por los bosques narrativos. Barcelona: Lumen, 1996.

Espinosa, Raúl. “Consideraciones geopolíticas a la realidad ecuatoriana”. Revista de las fuerzas armadas s/n (Quito, oct. 1989): 78-81.

Falconí, Fidel. Fuerzas armadas y movimiento indígena: la visión de las fuerzas armadas sobre el problema indígena en el Ecuador. Tesis para la obtención de la Maestría en Ciencias Políticas. Quito: FLACSO, 1991. 
Fiallo F., Fernando. “El problema indígena y su influencia en la estabilidad política del país”. Quito: IAEN, 1992.

Fitch, John Samuel. The Military Coup d'Etat as a Political Process: Ecuador, 19481966. Baltimore: Johns Hopkins University Press, 1977.

García, Bertha. "El 20 de abril: presente y pasado de un proyecto militar corporativo". Íconos. Revista de Ciencias Sociales 23 (Quito, set. 2005): 93-100.

"Militares, economía y lucha política: Ecuador en los años 70". (Tesis para la obtención de Maestría, Colegio de México) Quito: CONUEP/PUCE, 1986.

Ginzburg, Carlo. "Mitología germánica y nazismo. Acerca de un viejo libro de Georges Dumezil”. Mitos, emblemas, indicios. Morfología e historia. Barcelona: GEDISA, 1999.

GNR (Gobierno Revolucionario y Nacionalista del Ecuador). Filosofía y Plan de Acción. Quito: 1972.

Gudiño, Nelson. El problema indígena frente a la integración nacional. (Ensayo final elaborado en el posgrado en Seguridad y Desarrollo). Quito: IAEN, 1991.

Guerrero, Carlos A. “Función social del Oficial”. El Ejército Nacional 18 (Quito, 1924): 234-6.

Guevara, Arturo. “La Cooperativa de Producción Agrícola de Ahorro y Crédito ‘Taura’”. Revista de las fuerzas armadas 2 (Quito, 1967): 125-9.

Hurtado, Osvaldo. El poder político en el Ecuador. Quito: Centro de Publicaciones de la Pontificia Universidad Católica del Ecuador, 1977.

Kaldor, Mary. Las nuevas guerras: la violencia organizada en la era global. Barcelona: Tusquets, 2001.

Larrea, Salomón. "El servicio militar obligatorio conceptuado bajo los siguientes puntos para que este acuerdo esté con los intereses del Estado”. Revista de Estudios Históricos Militares VII/41 (Quito, 1928): 294-304.

Loveman, Brian. For la Patria: Politics and the Armed Forces in Latin America. Wilmington: SR Books, 1999.

Ministerio de Defensa Nacional. "Fuerzas armadas y movimiento Indígena realizaron histórico encuentro”. Revista de las fuerzas armadas 110 (Quito, oct. 1993): 70-5.

Molina Flores, Alberto. Las fuerzas armadas ecuatorianas paz y desarrollo. Quito: ALDHU, 1993.

Muñoz, Julio H. Doctrinas militares aplicadas en el Ecuador; historia y pedagogía militar. Quito: s/e, 1949.

Muratorio, Blanca, ed. "Discursos y silencios sobre el indio en la conciencia nacional”. Imágenes e imagineros. Quito: FLACSO, 1994. 9-24.

Nunn, Frederick M. “An Overview of the European Military Missions in Latin America”. The Politics of Antipolitics. Brian Loveman \& Thomas Davies Jr., eds. Wilmington: SR Books, 1997. 32-34.

Ortiz, Cecilia. Indios, militares e imaginarios de nación en Ecuador del siglo XX. Quito: FLACSO-Abya Yala, 2006.

Páez, Alexei. Los orígenes de la izquierda ecuatoriana. Quito: FIAAM-Abya Yala, 2001. 
Pallares Ayala, Amalia. “Construcciones raciales, reforma agraria y movilización indígena en los años 70”. Ecuador racista. Emma Cervone \& Fredy Rivera, eds. Quito: FLACSO, 1999. 159-72.

Paz, Clotario E. Larrea Alba, nuestras izquierdas. Guayaquil: Tribuna Libre, 1938.

Pazmiño, Arturo. “¿Tiene vigencia la sociedad rural y agraria en Ecuador?”. (Monografía final elaborada para el posgrado en Seguridad y Desarrollo). Quito: IAEN, 1976.

Rodríguez Lara, Guillermo. "Estamos trabajando”. Revista de las fuerzas armadas 47 (Quito: 1973): 16-21.

Rouquié, Alain. El Estado militar en América Latina. México: Siglo XXI, 1984.

“Dictadores, militares y legitimidad en América Latina”. Dictaduras y dictadores: una reflexión teórica sobre sus peculiaridades en América Latina, junto al análisis de los regímenes de Rosas, Francia, García Moreno, Gómez y Vargas y una guía bibliográfica para su estudio. Buenos Aires: Crítica \& Utopía, 1981.

Selmeski, Brian. "Multicultural Citizens, Monocultural Men: Indians, Conscription, and Development in the Ecuadorian Army”. Dissertation abstract, summary, and outline (mimeo), 2003.

"Warriors and Citizens: Racial Stereotypes and Military Roles of Ecuadorian Indigenous Conscripts”. Paper prepared for REDES 2001. Nueva York: Syracuse University/Quito: Pontificia Universidad Católica del Ecuador, 2001.

Serrano, Obdulio. Inauguración de la Carretera al Puyo. Quito: Departamento de Obras Públicas Militares del Ministerio de Defensa Nacional, 1946.

Varas, Augusto y Fernando Bustamante. Fuerzas armadas y Política en Ecuador. Quito: Ediciones Latinoamérica, 1978.

Velasco, Fernando. "La política y las fuerzas armadas: análisis crítico a partir de la Revolución Juliana”. Monografía final de Posgrado en Seguridad y Desarrollo. Quito: IAEN, 1990. 